\title{
Growth of (Platanus orientalis L.) Seedlings under Different Drought Stress Condition
}

\author{
Halmat A. Sabr* \\ Department of Forestry, College of Agricultural Engineering Sciences, Salahaddin University, Erbil, Kurdistan Region, Iraq
}

\section{*Corresponding author: Halmat A. Sabr, Department of Forestry, College of Agricultural Engineering Sciences, Salahaddin University, Erbil, Kurdistan Region, Iraq. E-mail: halmat. sabr@su.edu.krd}

Received: 12 March 2021

Accepted: 13 July 2021

Published: 30 December 2021

DOI

10.25156/pti.v11n2y2021.pp31-36

\section{A B S T R A C T}

A lath house study was performed in order that understand the adjustment responses to three different water conditions of Platanus orientalis L. seedlings trying to make them able to adjust to new under dry conditions. Eight months seedlings were exposed to three water regimes 190,60 and $30 \%$ water holding capacity $[\mathrm{WHC}]$ ) were used $r$ with a completely randomize design. The following parameters were measured; seedling height, leaf area, total chlorophyll content in the leaves, root length, root to shoot ratio, total dry mass, and leaf area ratio. It is found that water stress significantly reduced height and base diameter of seedlings, total chlorophyll per leaf, biomass allocation. The highest mean of leaf area, chlorophyll content, total dry mass, and moisture content were found under the treatment of $90 \%$ and $60 \%$ (WHC). However, the highest mean in root length was obtained under $30 \%$ of (WHC). The data show that $30 \%$ of (WHC) reduce seedling growth of $P$. orientalis $\mathrm{L}$., on the other hand, seedlings showed positive responses to $90 \%$ and 60 of (WHC) in this research. Variations in root length can be used as an indicator for planting this species and tree development under drought stress condition.

Keywords: Leaf area ratio; Platanus orientalis L. seedling; Root shoot ratio; Water holding capacity

\section{INTRODUCTION}

Oriental plane (Platanus orientalis L.) belongs to Platanaceae family. It is native to southeast Europe and southwest Asia. It is a deciduous tree with a spreading crown and growing up to height with $30 \mathrm{~m}$. Young branches are yellow-brown and hairy, however with getting older branches are become hairless. Leaves are intensely divided into 3, 5 or 7 lobes with coarsely toothed margins. Flowers are inconspicuous; however are bear in dense, spherical clusters hanging down on a long peduncle which is called stalk (Tree Guide, 2020).

An increase in atmospheric greenhouse gases that cause rise in the Earth's surface temperature to $0.74^{\circ} \mathrm{C}$ due to climate change (IPCC, 2007). In dry areas of the world because of a combination of declining water supply and soil nitrogen $(\mathrm{N})$ concentrations are commonly notable for their low primary productivity (Peek and Forseth, 2003). An extreme episode of climate change may possibly take on the adaptive ability of plants with decreased ability of plant's to cope with changes in its environment (Leimu et al., 2010). Water limitation is projected to have a negative effect on growth of native plants (Theurillat and Guisan, 2001). In addition, drought stress mainly causes decreasing in photosynthesis, which is the key mechanism of primary metabolisms and productivity (Chaves et al., 2009). Water content in a soil is a fundamental factor determining morphological characteristics such as the diameter of trees (DBH) (Orwig and Abrams, 1997) and as well as tree height (Koch et al., 2004).

It is well known that plants can have a short term physiological responses to water limitation. Water stress condition also alters in leaf chlorophyll content is a short-term reaction to drought stress, and it could be a source of making modification of stress condition (Ahmadi and Ceiocemardeh, 2004). According to Baker (2008) that water limitation stress can reduce chlorophyll concentration and cause a reduction in photosynthesis process and subsequently reduced plant growth. Rainfall may affect the photochemical action of chloroplasts as documented by Guo-Shun (2003), with water being the source used for transporting nutrients in plants, such as mineral salts to be absorbed by plants need to be dissolved in water $(\mathrm{Li}$ et al., 2018). Chlorophyll synthesis and water content are closely interrelated. During the period of water deficiency in leaves affects the synthesis of chlorophyll and increase the decomposition of chlorophyll, and expediting leaf yellowing (Li et al., 2018).

In Erbil city, P. orientalis L. is widely used for planting a long side roads and parks for providing ecological benefits such as shading, shelter for wildlife birds and other health benefits. It has been used as an ornamental tree in gardens 
and parks. Due to amount of rainfall in Erbil city is under variation every year. To plant this species and increasing plantation for providing ecological and recreation services. The objective for the present study was to determine the influences of different watering treatments during the hardening phase on morphology and physiology traits of the Plane tree seedlings under prediction of reducing amount of winter rainfall.

\section{MATERIALS AND METHODS}

\section{Description of the Experiment}

The study was conducted in the lath house in Grdarasha field of the college of Agricultural Engineering Sciences, Salahaddin University, Erbil Kurdistan region, Iraq.

\section{Plant materials}

The seedlings of plane tree (P. orientalis L.) were used at 8 months old approximately their height ranged $30-40 \mathrm{~cm}$. Seedlings were transplanted from plastic bags into plastic pods before conducting an experiment. Loamy soil was used for seedling growth. They were subjected to water limitation with different treatments for 60 days.

\section{Determination of field capacity (FC)}

A pot trial was also determined the FC of disturbed soil as follows. A pot was taken that used in the experiment. A surface of pot was cover by thin plastic film with proving several holes at bottom of pot to drain free water, but soil particles must not remove with drain water. Take a $7 \mathrm{~kg}$ of soil in pot. The pot soil was saturated for several hours with excess water consequently, all micro pores will filled up by water and cover the top of pot to avoid evaporation. When the gravitational water will seize (overnight), weigh net weight of moist soil was evaluated then the amount of water held by soil was calculated for example, 100\% FC. Subsequent calculate Water held at 80 and $90 \%$ of FC.

\section{Experiment design and statistical analysis}

The study was conducted as a simple experiment in a complete randomized design with one factor and three levels of drought was conducted. Bearing three drought stress levels; D0; $90 \%$ or full water holding capacity (WHC), D1; $60 \%$ of WHC and D2; 30\% of WHC distributed into five replications of experimental units over all 15 experimental units were used. The mean of 3 data were compared using Duncan's multiple range test DMRT IBM SPSS Statistics version 25 was used to analyze the data.

\section{Studied Parameters}

After 8 weeks between (10 September, 2020 and 10 November, 2020) of the growing period the following parameters were estimated:
The percentage of seedling mortality and survival: According to Engelbrecht et al. (2005) mortality and survival were calculated from below equations

$$
\begin{gathered}
\text { Mortality }=\frac{N 0-N 8}{N 0} \times 100 \\
\text { Survival }=\frac{N 8}{N 0} \times 100
\end{gathered}
$$

$\mathrm{N}_{0}=$ number of seedlings at the beginning research

$\mathrm{N}_{8}=$ number of survival seedlings after 8 weeks

\section{Seedling height $(\mathrm{cm})$}

The seedling heights $(\mathrm{cm})$ were measured from the base of seedling to terminal buds.

\section{Shoot fresh and dry biomass}

To calculate the fresh (FW) and dry (DW) weights of the biomasses, a digital balance was used. For DW determination, samples were oven-dried at $72^{\circ} \mathrm{C}$ in the oven until a constant weight of leaves and shoots $(\mathrm{g})$ were obtained.

\section{Total chlorophyll content in the leaves was measured by the use of at leaf chlorophyll meter STD handle}

It is a powerful, handheld, easy to use device for noninvasively measuring the relative chlorophyll content of green leaf plants. Measuring system is an optical density difference at 2 wavelengths ( $640 \mathrm{~nm}$ and $940 \mathrm{~nm}$ ) and a device calculate numerical SPAD value which is proportional to the amount of chlorophyll present in the leaf. The chlorophyll content is simply measured by placing the leaf into the aperture of the device (Mendoza-Tafolla et al., 2019).

Leaf area $\left(\mathrm{cm}^{2}\right)$ was estimated from below equation $\mathrm{LA}=20.912199+0.408927 *(\mathrm{~L} * \mathrm{~W})($ Sabr, 2020) where, $\mathrm{L}=$ leaf length, $\mathrm{W}=$ leaf width.

\section{Root to shoot ratio}

This was calculated by dividing root dry weight by shoot dry weight.

\section{Root length $(\mathrm{cm})$}

Root length was measured using of ruler from the base of vegetative growth to the end of root tip.

\section{Leaf area ratio (LAR) was calculated from the following equation \\ LAR = leaf area/total plant biomass}

Moisture content (M\%)

The moisture content of shoots and roots were calculated depending on fresh weight (FW) and dry weight (DW) of seedlings (Zhou and Qiu, 2005). 
$M \%=\frac{F W-D W}{F W} * 100$

\section{RESULTS AND DISCUSSION}

Even though, all seedlings still alive under water stress condition from the present finding data which is related to watering treatments. For the period of reducing water content in the soil a significant reduction was found for seedling height under $30 \%$ of (WHC) treatment. The highest values were obtained $(45.2 \mathrm{~cm})$, while the lowest mean were recorded in the D2 treatment $(43.40 \mathrm{~cm})$ [Table 1] [See Appendix 1]. In addition, it is found that seedling leaf area and total chlorophyll per leaf were significantly increased under well water condition demonstrating the development of leaf morphology and physiology parameters. However, these measurements were significantly decreased with the treatment of $30 \%$ of (WHC) with the highest data were recorded for D0 (83.7 and 35.2 per leaf), whereas the lowest means were obtained in the treatment of (D2) [Table 2] [See Appendix 2]. Table 3 demonstrates measured physiological parameters of $P$. orientalis L. seedlings. The results from the end of the experiments indicates that a significant differences were found for total dry mass, LAR and moisture content $(\mathrm{MC} \%$ ) with the treatment of 90 and $60 \%$ of (WHC), while under drought condition with 30\% of (WHC) a significant increase was found for both root length and root to shoot ratio compare to other treatments [Table 3]. Furthermore for the last mentioned parameter $(\mathrm{R} / \mathrm{S})$ seedling grown under 60\% (WHC) showed the lowest mean value (1.46) in comparison to (D2) [See Appendix 3].

A number of tree functions are an able to act in natural way, when soil water is progressively decreased. Mainly, the drought condition treatment resulted in wilting leaves but not mortality thus most of the seedlings were survived personal observation. Levitt (1980) stated that there are two processes plants can resist drought condition. Whole-plant responses to water stress range from stomata closure to increased root/shoot ratio, leaf area reduction. Such that mechanisms either increase water availability or reduce water loss, in that way increasing plant water-use efficiency but decreasing biomass productivity (Levitt, 1980). First and foremost trees avoid water limitation through adjustment of morphological and anatomical parameters even though with decreasing efforts in the environment to which trees are not covered to preserve favorable internal water potential (Barnes et al., 1997). As documented by Tyree et al. (2003) that adjustment through physiological processes such as mechanism of desiccation tolerance is one of the essential features for seedling survival under dry condition. Apart from a study was that the effect of water stress on morphological features was very important in $P$. orientalis $\mathrm{L}$. seedlings. Seedlings from D0 and D1 showed higher mean seedling height as compare to water stress condition. The results are in accordance with other studies such as Royo and Pardos (2001) on Pinus halepensis Mill. Tree. Similar results have been documented in other tree species, for example Quercus suber L. seedlings (Puértolas et al., 2008), Picea asperata (Yang et al., 2008), Populus cathayana (Lu et al., 2009), Abies fabri (Yang et al., 2013), and Brachychiton populneus (Karim et al., 2020).

Leaf area and total chlorophyll content decreased significantly because of drought treatments when the highest levels were obtained in the control (D0). Acclimation to slowly decreasing soil water availability occurs before the commencement of tissue dehydration and results in physiological and morphological adjustments that improve plant water balance (Pereira and Chaves, 1993). A plant's ability to prolong moderate stress or postpone severe stress and thereby maintain a more favorable leaf water

Table 1: Effects of drought treatments on mortality, survival, seedling height measurements

\begin{tabular}{lccc}
\hline Treatments & Mortality \% & Survival \% & Final height $(\mathbf{c m})$ \\
\hline D0 & 0 & 100 & $45.20^{\mathrm{a}}$ \\
D1 & 0 & 100 & $45.40^{\mathrm{ab}}$ \\
D2 & 0 & 100 & $43.40^{\mathrm{b}}$ \\
\hline
\end{tabular}

D0 $=90 \%$ or full water holding capacity (WHC); $\mathrm{D} 1=60 \%$ of WHC and; $\mathrm{D} 2=30 \%$ of WHC. The values with the same letters were not significantly different among means according to the Duncan's multiple range

Table 2: Effect of drought treatments on morphology and physiology of leaf measurements

\begin{tabular}{lcccc}
\hline Treatments & $\begin{array}{c}\text { Leaf } \\
\text { length }\end{array}$ & $\begin{array}{c}\text { Leaf } \\
\text { width }\end{array}$ & $\begin{array}{c}\text { Leaf area } \\
\mathbf{c m}^{2}\end{array}$ & $\begin{array}{c}\text { chlorophyll } \\
\text { per leaf }\end{array}$ \\
\hline D0 & $12.88^{\mathrm{a}}$ & $12.02^{\mathrm{a}}$ & $83.7^{\mathrm{a}}$ & $35.2^{\mathrm{a}}$ \\
D1 & $10.80^{\mathrm{b}}$ & $9.00^{\mathrm{b}}$ & $65.4^{\mathrm{b}}$ & $32.0^{\mathrm{b}}$ \\
D2 & $10.12^{\mathrm{b}}$ & $7.98^{\mathrm{c}}$ & $55.5^{\mathrm{c}}$ & $25.80^{\mathrm{c}}$ \\
\hline
\end{tabular}

The values with the same letters were not significantly different among means according to the Duncan's multiple range

Table 3: Effects of drought treatments on root length, total dry mass (g), moisture content (\%), root to shoot ratio and leaf area ration measurements

\begin{tabular}{lccccc}
\hline Treatments & Root length $(\mathrm{cm})$ & Total dry mass $(\mathrm{g})$ & Moisture content \% & Root to shoot ratio & Leaf area ratio \\
\hline D0 & $31.0^{\mathrm{c}}$ & $14.28^{\mathrm{a}}$ & $54.20^{\mathrm{a}}$ & $1.48^{\mathrm{a}}$ & $6.61^{\mathrm{a}}$ \\
D1 & $36.1^{\mathrm{b}}$ & $12.93^{\mathrm{b}}$ & $56.80^{\mathrm{ab}}$ & $1.46^{\mathrm{a}}$ & $4.50^{\mathrm{b}}$ \\
D2 & $39.4^{\mathrm{a}}$ & $8.85^{\mathrm{c}}$ & $50.60^{\mathrm{c}}$ & $1.84^{\mathrm{a}}$ & $6.79^{\mathrm{a}}$ \\
\hline
\end{tabular}

The values with the same letters were not significantly different among means according to the Duncan's multiple range 
status during the first phase of a drought may enable the plant to avoid damage by severe water stress later on (Silva et al., 2004). Ranjbarfordoei et al. (2000) stated that as a result of water limitation condition energetic status of the chloroplast enhances which has a direct relationship to that of increased amount of total chlorophyll and chlorophyll a and chlorophyll $\mathrm{b}$ between the stressed stimulated verities. The same results for determination of total chlorophyll were found under mild to severe water stress by Ahmadikhah and Marufinia (2016). Wright et al., (2004) stated that it may be due to that leaves are the most important photosynthetic and biological structure of plants An increase in density of foliar tissue with lower specific leaf area and decrease in net $\mathrm{CO}_{2}$ assimilation rate were also found in leaves of Olea europaea cv. tree (Guerfel et al., 2009). In addition, as water availability decreased the size of leaves tends to reduce as well (Cramer et al., 2009). In general plants grown under hot and dry environment and at high intensities of sun light leaves with smaller sizes are taking beneficial with higher efficiency energy gas exchange ability (Tozer et al., 2015). As mentioned above that leaves are the most important photosynthetic structure leaf sizes such as leaf width and length and leaf area greatly influence a different of biological mechanisms, for example, plant growth and survival (Tozer et al., 2015).

The present study showed that higher biomass production, moisture content and LAR were significantly increased in $90 \%$ of WHC condition. Patterson et al. (1997) stated that characterized by adaptation restraints in morphology parameter could be the main mechanism by which this species can survive with in drought condition stress. The results were in agreement with other previously studies for example, for arid ecosystems (James et al., 2005) and for Kurrajong tree seedlings by Karim et al. (2020). Furthermore, under water stress condition plants frequently diminish biomass allocation into root biomass in order that reduce utilization and absorption more water from the soil, so that are able to preserve a higher root to shoot ratio (Villagra and Cavagnaro, 2006). A higher mean root length was found under water limitation treatments. Root systems can be defined that as a complex and characterized by constant change structures, thus water absorption may be restricted by the amount of roots distribution in a special soil layer and further improvement of root growth can enhance drought-tolerance (Klepper and Rickman, 1990). An increase in root length were greater in water-stressed seedlings as compare to well-watered seedlings, demonstrating that decreasing water availability had less effect on root growth than on leaf growth (Hsiao and $\mathrm{Xu}, 2000)$. It is also documented in an investigation by Kozlowski and Pallardy (2002) that under drought condition the length and quantity activity of root system as well as increased. Improved dry mass allocation to roots may be resulted from a drought-induced reduction in the sink strength of the aboveground plant tissues, making more assimilates available for root growth (Silva et al., 2004). Correspondingly, comparing two clones of Populus tree that tolerate clones showed higher carbon allocation to roots biomass throughout the duration of the early seedling stage of drought stress (Tschaplinski et al., 1998). Water deficit mostly reduced leaf growth and increased at least relatively dry matter allocation into the root fraction, leading to a significant raise of root mass into foliage area ratio or root/shoot ratio under drought stress (Yin et al., 2005). The data found were also in agreement with this theory of that decreased seedling leaf area was to achieve aim water stress avoidance for the seedlings by reducing transpiration (Villagra and Cavagnaro, 2006).

\section{CONCLUSION}

The data from present study showed that an increase drought stress was significantly influenced morphological and physiological parameter of $P$. orientalis L. Water stress condition is a conventional method to develop performance of this species seedling in water stress areas. Higher biomass was found in less than $90 \%$ of SWHC. However, decreasing soil water holding with less than $60 \%$ significantly effect on growth performance of seedlings, but the root length feature is accepted to be more water deficit tolerance.

\section{ACKNOWLEDGMENT}

The author is greatly thanks Dr. Sirwa A. Qader for helping conducting this research and I would like to thank college of Agricultural Engineering Sciences and Forestry department for providing the study location.

\section{REFERENCES}

Ahmadi, A. and A. Ceiocemardeh. 2004. Effect of drought stress on soluble carbohydrate, chlorophyll and Proline in four adopted wheat cultivars with various climate of Iran. Iran. J. Agric. Sci. 35: 753-763.

Ahmadikhah, A. and A. Marufinia. 2016. Effect of reduced plant height on drought tolerance in rice. 3 Biotech. 6(2): 1-9.

Baker, N. R. 2008. Chlorophyll fluorescence: A probe of photosynthesis in vivo. Annu. Rev. Plant Biol. 59: 89-113.

Barnes, B.V., D. R. Zak, S. R. Denton and S. H. Spurr. 1997. Forest Ecology. $3^{\text {rd }}$ ed. John Wiley and Sons, New York, United States.

Chaves, M. M., J. Flexas and C. Pinheiro. 2009. Photosynthesis under drought and salt stress: Regulation mechanisms from whole plant to cell. J. Ann. Bot. 103(4): 551-560.

Cramer, M. D., H. J. Hawkins and G. A. Verboom. 2009. The importance of nutritional regulation of plant water flux. J. Oecol. 161(1): 15-24.

Engelbrecht, B. M., T. A. Kursar and M. T. Tyree. 2005. Drought effects on seedling survival in a tropical moist forest. J. Trees. 19(3): 312-321. 
Guerfel, M., O. Baccouri, D. Boujnah, W. Chaïbi and M. Zarrouk. 2009. Impacts of water stress on gas exchange, water relations, chlorophyll content and leaf structure in the two main Tunisian olive (Olea europaea L.) cultivars. J. Sci. Hortic. 119(3): 257-263.

Guo-Shun, Z.H.O. 2003. Effect of water stress on photochemical activity of chloroplast from wheat. J. Beijing Agric. Coll. 3: $180-190$.

Hsiao, T. C. and L. K. Xu. 2000. Sensitivity of growth of roots versus leaves to water stress: Biophysical analysis and relation to water transport. J. Exp. Bot. 51(350): 1595-1616

IPCC. 2007. The physical science basis In: Solomon, S., D. Qin, M. Manning, Z. Chen, M. Marquis, K. B. Averyt and H. L. Miller, editors. Contribution of Working Group I to the Fourth Assessment Report of the Intergovernmental Panel on Climate Change. Cambridge University Press, Cambridge.

James, J. J., R. L. Tiller and J. H. Richards. 2005. Multiple resources limit plant growth and function in a saline-alkaline desert community. J. Ecol. 93(1): 113-126.

Karim, S. A., S. A. Qadir and H. A. Sabr. 2020. Study some of morphological and physiological traits of Kurrajong Brachychiton populneus (Schott \& Endl.) seedlings planted under water stress conditions. Basrah J. Agric. Sci. 33(1): 213-220.

Klepper, B. and R. W. Rickman. 1990. Modeling crop root growth and function. Vol. 44. In: Advances in Agronomy. Academic Press, Massachusetts, United States. p113-132.

Koch, G. W., S. C. Sillett, G. M. Jennings and S. D. Davis. 2004. The limits to tree height. J. Nat. Sci. 428(6985): 851-854.

Kozlowski, T. T. and S. G. Pallardy. 2002. Acclimation and adaptive responses of woody plants to environmental stresses. Bot. Rev. 68(2): 270-334.

Leimu, R., P. Vergeer, F. Angeloni and N. J. Ouborg. 2010. Habitat fragmentation, climate change, and inbreeding in plants. Ann. N. Y. Acad. Sci. 1195(1): 84-98.

Levitt, J. 1980. Responses of plants to environmental stresses. In: Water, Radiation, Salt, and Other Stresses. $2^{\text {nd }}$ ed., Vol. 2. Academic Press, Massachusetts, United States.

Li, Y., N. He, J. Hou, L. Xu, C. Liu, J. Zhang, Q. Wang, X. Zhang and X. Wu. 2018. Factors influencing leaf chlorophyll content in natural forests at the biome scale. Front. Ecol. Evol. 6: 64.

Mendoza-Tafolla, R. O., P. Juarez-Lopez, R. E. Ontiveros-Capurata, M. Sandoval-Villa, A. T. Iran and G. Alejo-Santiago. 2019. Estimating nitrogen and chlorophyll status of romaine lettuce using SPAD and at LEAF readings. Not. Bot. Horti Agrobot. ClujNapoca. 47(3): 751-756.

Orwig, D. A. and M. D. Abrams. 1997. Variation in radial growth responses to drought among species, site, and canopy strata. Trees. 11(8): 474-484.

Patterson, T. B., R. D. Guy and Q. L. Dang. 1997. Whole-plant nitrogen-and water-relations traits, and their associated tradeoffs, in adjacent muskeg and upland boreal spruce species. J. Oecol. 110(2): 160-168.

Peek, M. S. and I. N. Forseth. 2003. Microhabitat dependent responses to resource pulses in the aridland perennial, Cryptantha flava. J. Ecol. 91(3): 457-466.

Pereira, J. S. and M. M. Chaves. 1995. Plant responses to drought under climate change in Mediterranean-type ecosystems. In:
Global Change and Mediterranean-Type Ecosystems. Springer, New York. p140-160.

Puértolas, J., M. Pardos, M. D. Jiménez, I. Aranda and J. A. Pardos. 2008. Interactive responses of Quercus suber L. seedlings to light and mild water stress: Effects on morphology and gas exchange traits. J. Ann. For. Sci. 65(6): 611-611.

Ranjbarfordoei, A., R. Samson, P. van Damme and R. Lemeur. 2000. Effects of drought stress induced by polyethylene glycol on pigment content and photosynthetic gas exchange of Pistacia khinjuk and P. mutica. J. Photosynth. 38(3): 443-447.

Royo, A., L. Gil and J. A. Pardos. 2001. Effect of water stress conditioning on morphology, physiology and field performance of Pinus halepensis Mill. seedlings. J. New For. 21(2): 127-140.

Sabr, H. A. 2020. Prediction of leaf area by a non-destructive method of Platanus orientalis tree. J. Duhok Univ. 23(2): 211-217.

Silva, F. C. E., A. Shvaleva, J. P. Maroco, M. H. Almeida, M. M. Chaves and J. S. Pereira. 2004. Responses to water stress in two Eucalyptus globulus clones differing in drought tolerance. J. Tree Physiol. 24(10): 1165-1172.

Theurillat, J. P. and A. Guisan. 2001. Potential impact of climate change on vegetation in the European Alps: A review. Clim. Change. 50(1): 77-109.

Tozer, W. C., B. Rice and M. Westoby. 2015. Evolutionary divergence of leaf width and its correlates. Am. J. Bot. 102: 367-378.

Tree Guide. 2020, Oriental Plane Tree. Available from: http:// www.tree-guide.com/oriental-plane-tree [Last accessed on 2021 Mar 05].

Tschaplinski, T. J., G. A. Tuskan, G. M. Gebre and D. E. Todd. 1998. Drought resistance of two hybrid Populus clones grown in a large-scale plantation. J. Tree Physiol. 18(10): 653-658.

Tyree, M. T., B. M. Engelbrecht, G. Vargas and T. A. Kursar. 2003. Desiccation tolerance of five tropical seedlings in Panama. Relationship to a field assessment of drought performance. J. Plant Physiol. 132(3): 1439-1447.

Villagra, P. E. and J. B. Cavagnaro. 2006. Water stress effects on the seedling growth of Prosopis argentina and Prosopis alpataco. J. Arid Environ. 64(3): 390-400.

Wright, I. J., N. Dong, V. Maire, I. C. Prentice, M. Westoby, S. Díaz, R. V. Gallagher, B. F. Jacobs, R. Kooyman, E. A. Law and M. R. Leishman. 2017. Global climatic drivers of leaf size. Sci. J. 357(6354): 917-921.

Yang, Y., C. Han, Q. Liu, B. Lin and J. Wang. 2008. Effect of drought and low light on growth and enzymatic antioxidant system of Picea asperata seedlings. J. Acta Physiol. Plant. 30(4): 433-440.

Yang, Y., G. Wang, L. Yang and J. Guo. 2013. Effects of drought and warming on biomass, nutrient allocation, and oxidative stress in Abies fabri in Eastern Tibetan Plateau. J. Plant Growth Regul. 32(2): 298-306.

Yin, C., X. Wang, B. Duan, J. Luo and C. Li, C. 2005. Early growth, dry matter allocation and water use efficiency of two sympatric Populus species as affected by water stress. J. Environ. Exp. Bot. 53(3): 315-322.

Zhou, W. and B. Quu. 2005. Effects of cadmium hyperaccumulation on physiological characteristics of Sedum alfredii Hance (Crassulaceae). J. Plant Sci. 169(4): 737-745. 


\section{APPENDIX}

Appendix 1: ANOVAs table for the studied parameters of Platanus orientalis L. seedlings

\begin{tabular}{lccccc}
\hline & $\begin{array}{c}\text { Sum of } \\
\text { squares }\end{array}$ & df & $\begin{array}{c}\text { Mean } \\
\text { square }\end{array}$ & F & Sig. \\
\hline Seedling height (cm) & & & & & \\
$\quad$ Between Groups & 19.600 & 2 & 9.800 & .256 & .029 \\
Within Groups & 460.000 & 12 & 38.333 & & \\
$\quad$ Total & 479.600 & 14 & & & \\
Chlorophyll per leaf & & & & & \\
(SPAD) & & & & & \\
Between Groups & 226.325 & 2 & 113.163 & 9.723 & .003 \\
Within Groups & 139.668 & 12 & 11.639 & & \\
Total & 365.993 & 14 & & & \\
Leaf area LA (cm $\left.{ }^{2}\right)$ & & & & & \\
Between Groups & 2467.537 & 2 & 1233.769 & 2.556 & .019 \\
Within Groups & 5793.028 & 12 & 482.752 & & \\
Total & 8260.566 & 14 & & & \\
Root length (cm) & & & & & \\
Between Groups & 180.436 & 2 & 90.218 & 1.086 & .037 \\
Within Groups & 997.120 & 12 & 83.093 & & \\
Total & 1177.556 & 14 & & & \\
Total dry mass (g) & & & & & \\
Between Groups & 79.914 & 2 & 39.957 & 7.713 & .007 \\
Within Groups & 62.168 & 12 & 5.181 & & \\
Total & 142.082 & 14 & & & \\
Moisture content MC & & & & & \\
(\%) & & & & & \\
Between Groups & 96.933 & 2 & 48.467 & 1.005 & .039 \\
Within Groups & 578.800 & 12 & 48.233 & & \\
Total & 675.733 & 14 & & & \\
Root to shoot & & & & & \\
Between Groups & .434 & 2 & .217 & .470 & .054 \\
Within Groups & 5.546 & 12 & .462 & & \\
Total & 5.981 & 14 & & & \\
Leaf area ratio cm ${ }^{2} \mathrm{~g}-1$ & & & & & \\
Between Groups & 16.225 & 2 & 8.113 & 2.297 & .014 \\
Within Groups & 42.384 & 12 & 3.532 & & \\
Total & 58.609 & 14 & & & \\
\hline
\end{tabular}

